\title{
A STOCHASTIC MODEL TO DETERMINE THE ELEMENTS OF PRODUCTION CYCLE TIME IN ENTERPRISE
}

\author{
Milivoj KLARIN ${ }^{1}$, Vesna SPASOJEVIC BRKIĆ ${ }^{2}$, Sanja STANISAVLJEV ${ }^{3}$, \\ Zvonko SAJFERT ${ }^{3}$, Miroslav RADOJIČIĆ ${ }^{4}$, Milan NIKOLIĆ ${ }^{3}$, Bojan JOVANOVSKI ${ }^{5}$ \\ ${ }^{1}$ University of Novi Sad, Technical faculty "Mihajlo Pupin” in Zrenjanin, 23000 Zrenjanin, Djure Djakovica bb, \\ Republic of Serbia. E-mail: mklarin@open.telekom.rs \\ ${ }^{2}$ University of Belgrade, Faculty of Mechanical Engineering, Belgrade, Kraljice Marije 16, Republic of Serbia \\ ${ }^{3}$ University of Novi Sad, Technical faculty "Mihajlo Pupin" in Zrenjanin, 23000 Zrenjanin, Djure Djakovica bb, \\ Republic of Serbia. \\ ${ }^{4}$ University of Kragujevac, Techical Faculty, Čačak, Svetog Save 65, Republic of Serbia \\ ${ }^{5}$ Ss. Cyril and Methodi University, Faculty of Mechanical Engineering, Skopje, Republic of Macedonia
}

Accepted 17 October, 2012

\begin{abstract}
A model for the stochastic determination of the elements of production cycle time is proposed and experimentally verified in this survey. The originality of the model is reflected in the idea of using a work sampling model to monitor the production cycle, as one of the most significant indicators of production effectiveness and efficiency, instead of applying classical methods. It has been experimentally proved that for a corresponding representative set the elements of working time range according to normal distribution law and that, dynamically viewed, it is possible using mean value calculations to establish control limits on 3 standard deviations for the individual elements of working time and thus to master the process.
\end{abstract}

Key words: production cycle, work sampling, stochastic model.

\section{INTRODUCTION}

The most important organizational-technical indicators of production successfulness are the level of capacity utilization and the production cycle. These indicators are actually influenced by a series of organizational-technical, mutually interconnected, factors which impact on the elements of working time related to the machine capacity utilization and production cycle of a certain product. The goal is, in general, to reduce the total production cycle time, especially that associated with different types of stoppage and the optimization of lead time and machine time within the sphere of machine capacity utilization. Additionally, the optimization of time for transport, control, and packing is also of importance for the production cycle. Reduced cycle time can be translated into increased customer satisfaction. Quick response companies are able to launch new products earlier, penetrate new markets faster, meet changing demand, and make rapid and timely deliveries. They can also offer their customers lower costs because quick response companies have streamlined processes with low inventory and less obsolete stock.
Consequently, the aim of this paper is to set up a model for the stochastic determination of the elements of production cycle time. Using a modified work sampling method, it has been experimentally proved in this paper that for a corresponding representative set the elements of working time range according to normal distribution law. Also, dynamically viewed, it is possible using mean value calculations to establish control limits on 3 standard deviations for some individual elements of working time and thus to master the process.

\section{LITERATURE REVIEW}

In the past, in both theory and practice, increased attention was focused on the level of machine capacity utilization because machines were more costly and thereby had a greater impact on production effectiveness. A special contribution here was made by L. H. C. Tippett (1902-1985) who first applied his method of work sampling in the textile industry (according to Barnes, R., 1957). Nevertheless, the classical work sampling method established by Tippett (according to Barnes, R., 
1957; Maynard, 1971; Moder, 1980) is not appropriate for contemporary production systems, because in his research the main stoppage was due to poor material quality. Despite its shortcomings, this method is still used in production practice and is found in all industrial engineering text-books (Richardson and Eleanor, 1982). The indispensible modification of the method presented by Klarin et al. (2000) aims to explain and justify both the necessity and importance of using the shift level of the utilization of capacity as the stochastic variable in determining the total level of capacity utilization in the production process by using the method of work sampling on a sample comprising 74 Serbian companies. The conclusion drawn is that the shift level of capacity utilization as the stochastic variable in work sampling is the model which solves the problem of determining the total level of capacity utilization in a convenient way with accurate results. On the other hand, on the basis of Klarin et al. (2000), Elnekave and Gilad (2006) propose a digital video-based approach to enhance work measurement and analysis by facilitating the generation of rapid time standards, which serves as a computerized tool for remote work measurement with the ability to derive the rapid generation of time standards. The application of the modified work sampling method in the processing industry indicates that the methods of monitoring capacity utilization applied in the processing industry such as cement production may also be used in the metalworking industry which has a high level of capacity utilization. Hence, the results of the analysis indicate that when the level of capacity utilization is high, this variable may be observed per day as stochastic, while, per machine, it may be a random variable (Klarin et al., 2010). It is evident that today the more significant problem of monitoring and influencing the production cycle (the period from the item's entry into the production process to the receipt of a finished product and its packing) is by far less present in the literature.

In (Niebel, 1980) an experimental example illustrates the determination of the elements of production cycle time, showing that production cycle $\mathrm{C}$ is divided into only three elements of cycle time, $\mathrm{C}=\mathrm{T}_{1}+\mathrm{T}_{2}+\mathrm{T}_{3}$ where: $\mathrm{T}_{1}=$ running time to produce one unit of output, $\mathrm{T}_{2}=$ normal time to service a stopped machine and $\mathrm{T}_{3}=$ time lost by normal operator working because of machine interference.

In paper by Agrawal et al. (2000) an approach to improve MRP-based production planning by means of targeting minimal product cycle times is presented. A number of works (Giri and Yun, 2005;
Tzu-Hsien, 2009) consider the impact of machine breakdown on production cycle time, while Barbiroli and Raggi (2003) studied technical and economic performances related to innovations in the production cycle environment. An inventory model is linked with production cycle optimization in (Kun-Jen et al., 2009), whereas paper (Kodek and Krisper, 2004) gives an optimal algorithm for minimizing production cycle time for assembly lines, using linear mathematical programming which requires extensive calculations.

Models based on stochastic functions, or instantaneous observation methods (work sampling), have not been encountered in literature despite their ability to offer a simpler but accurate enough solution to the problem.

\section{THE BASICS OF A STOCHASTIC MODEL TO DETERMINE THE ELEMENTS OF PRODUCTION CYCLE TIME}

For the purpose of analysis, the production cycle is essentially divided into production time $-t_{p}$ and nonproduction time $t_{n p}$ (Čala et al., 2011). Nonproduction time involves diverse stoppage factors related directly or indirectly to man's positive or negative attitude towards production. These stoppages, characteristic of small and medium-sized enterprises in the metalworking industry, are, as a rule, longer than the necessary production times and are more difficult to shorten. The optimal production cycle is that which is the shortest for the same product quality and price. The most common division of production cycle time in literature is production time $-t_{p}$ divided into technological time $-t_{t}$, with machine $t_{t m}$ and lead time $t_{p f}$, nontechnological time $-t_{n t}$ with time of control $-t_{c}$, transportation $-t_{\mathrm{tr}}$ and packaging $-\mathrm{t}_{\mathrm{pk}}$. Nonproduction time is classified according to various causes of stoppages in production, and we have made the screening of the most general and common ones caused by the lack of raw materials $-t_{m r}$, tools $-t_{t}$, organization $-t_{o}$, machine breakdown $-t_{b}$ and

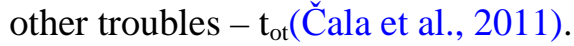

The representativeness of a screening sample per number and time of screening was established by mathematical parameters, SD and control limits, where the elements of PC time are observed as the elements of the process function (Barnes, 1957; Maynard, 1971; Moder, 1980; Niebel, 1980; Richardson and Eleanor, 1982; Klarin et al., 2010; Čala et al., 2011). 


\section{A STOCHASTIC MODEL - THE APPLICATION}

The model was applied in 2011 and involved a larger number of Serbian enterprises. The results obtained for three characteristic enterprises will be presented here.

Table 1: Scheme with the results of screening

\begin{tabular}{|c|c|c|c|c|c|c|c|c|c|c|c|c|c|c|}
\hline \multirow{2}{*}{ Date } & \multirow{2}{*}{ No } & \multicolumn{2}{|c|}{ Time } & \multicolumn{5}{|c|}{ Production time tp } & \multicolumn{5}{|c|}{ Non-productive tnp } & \multirow{2}{*}{ Number of items } \\
\hline & & Start & End & tpt & $\mathrm{tm}$ & tc & ttr & tpk & tmr & tttl & to & tb & tto & \\
\hline 19.09.'11. & 26 & $8: 30$ & 13:00 & 3 & 9 & 3 & 1 & 2 & 2 & & 2 & 1 & 2 & 7 \\
\hline 26.09.'11. & 18 & $8: 05$ & $13: 30$ & 2 & 5 & 2 & 4 & 3 & 1 & & & & 1 & 10 \\
\hline 23.09.'11. & 21 & & & & & & & & 21 & & & & & CANCELLED SHIFT \\
\hline 19.09.'11. & 31 & $8: 30$ & 13:00 & 2 & 9 & 3 & 3 & 3 & 2 & 1 & 2 & 1 & 4 & 7 \\
\hline 19.09.'11. & 22 & $8: 20$ & $13: 10$ & 2 & 7 & 4 & 1 & 3 & 1 & & 2 & & 2 & 8 \\
\hline 12.10.'11. & 20 & $8: 45$ & $12: 45$ & 2 & 7 & 1 & 3 & 2 & & 1 & 1 & & 3 & 3 \\
\hline 30.09.'11. & 23 & $8: 20$ & $14: 33$ & 5 & 10 & 1 & 2 & 3 & & & & & 2 & 7 \\
\hline 03.10.'11. & 19 & $0: 00$ & 13:00 & 1 & 7 & 2 & 3 & 2 & & & & & 4 & 5 \\
\hline 03.10.'11. & 12 & $8: 50$ & $13: 38$ & 2 & 2 & 1 & 4 & 2 & & & & & 1 & 3 \\
\hline 07.10.'11. & 21 & $7: 52$ & $13: 40$ & 3 & 5 & 1 & 2 & 3 & & & & & 6 & 5 \\
\hline 26.09.' '11. & 17 & $8: 05$ & $13: 30$ & 2 & 3 & 3 & 2 & 3 & & 1 & & & 3 & 10 \\
\hline 03.10.'11. & 20 & $8: 50$ & $14: 10$ & 3 & 4 & 2 & 5 & 3 & & & & & 3 & 4 \\
\hline 03.10.'11. & 23 & $7: 41$ & $12: 50$ & 3 & 4 & 3 & 4 & 3 & & & 1 & & 5 & 6 \\
\hline 21.09.'11. & 17 & $8: 00$ & $13: 15$ & 3 & 3 & 1 & 3 & 1 & 2 & & & & 4 & 6 \\
\hline 07.10.'11. & 19 & $8: 00$ & 13:10 & 3 & 6 & 3 & 2 & 3 & & & & & 2 & 3 \\
\hline 30.09.'11. & 21 & $8: 32$ & $13: 40$ & 3 & 7 & 3 & 3 & 2 & & & & & 3 & 5 \\
\hline 21.09.'11. & 21 & 8:00 & $13: 50$ & 3 & 6 & 3 & 4 & 2 & 2 & & & & 4 & 5 \\
\hline 10.10.'11. & 19 & $7: 33$ & 13:00 & 2 & 4 & 3 & 4 & 2 & & & 1 & & 3 & 5 \\
\hline 17.10.'11. & 14 & $4: 54$ & 11:00 & 1 & 4 & 1 & 3 & 3 & & & & 1 & 1 & 8 \\
\hline 17.10.'11. & 12 & $4: 54$ & 11:00 & 1 & 2 & 1 & 2 & 3 & & & & 2 & 1 & 8 \\
\hline 19.10.'11. & 20 & $7: 42$ & $12: 35$ & 4 & 6 & 2 & 1 & 1 & & & 1 & 1 & 4 & 4 \\
\hline 19.10.'11. & 17 & $7: 50$ & $12: 35$ & 1 & 4 & 2 & 4 & 2 & & & & 1 & 3 & 4 \\
\hline 21.09.'11. & 19 & $8: 00$ & $14: 18$ & 2 & 5 & 2 & 3 & 2 & 1 & & & & 4 & 8 \\
\hline 14.10.'11. & 22 & $7: 24$ & $13: 15$ & 2 & 2 & 5 & 2 & 2 & 2 & & 1 & & 6 & 6 \\
\hline 14.10.'11. & 22 & $7: 24$ & $13: 15$ & 3 & 4 & 2 & 4 & 1 & 2 & & 1 & & 5 & 6 \\
\hline 28.09.'11. & 21 & $7: 39$ & $13: 15$ & 4 & 7 & 4 & 4 & 1 & & & & & 1 & 5 \\
\hline 14.10.'11. & 18 & $7: 24$ & $13: 15$ & 1 & 3 & 2 & 2 & 2 & & & 1 & & 6 & 6 \\
\hline 07.10.'11. & 13 & $7: 34$ & $11: 40$ & 1 & 2 & 2 & 1 & 2 & & & & & 5 & 5 \\
\hline 28.09.'11. & 21 & $7: 39$ & $13: 15$ & 3 & 8 & 1 & 4 & 1 & & & & & 4 & 5 \\
\hline 03.10.'11. & 20 & $7: 41$ & 13:00 & 2 & 5 & 1 & 4 & 2 & & & & & 6 & 5 \\
\hline 28.09.'11. & 18 & $9: 23$ & $14: 00$ & 1 & 5 & 2 & 3 & 1 & 1 & & & & 5 & 5 \\
\hline 12.10.'11. & 16 & $8: 45$ & $14: 20$ & 2 & 3 & 2 & 4 & 2 & 1 & & & & 2 & 8 \\
\hline 12.10.'11. & 14 & $6: 33$ & $12: 40$ & 1 & 5 & 2 & 2 & 2 & & & 1 & & 1 & 6 \\
\hline 12.10.'11. & 22 & $6: 33$ & $12: 40$ & 1 & 7 & 3 & 6 & 2 & & & 1 & & 2 & 6 \\
\hline 10.10.'11. & 17 & $7: 33$ & $12: 50$ & 2 & 3 & 4 & 3 & 1 & & & 1 & & 3 & 5 \\
\hline 26.09.'11. & 23 & $8: 00$ & 15:00 & 1 & 4 & 5 & 4 & 3 & & & & & 6 & 10 \\
\hline 10.10.'11. & 19 & $7: 33$ & 13:00 & 2 & 4 & 3 & 4 & 2 & & & 1 & & 3 & 5 \\
\hline 24.10.'11. & 16 & $8: 15$ & $12: 38$ & 2 & 5 & 4 & 2 & 2 & & & & & 1 & 4 \\
\hline 28.10.'11. & 22 & 9:00 & $14: 45$ & 2 & 5 & 4 & 4 & 2 & 1 & & & & 4 & 5 \\
\hline 28.10.'11. & 21 & $8: 20$ & 14:10 & 1 & 4 & 3 & 3 & 3 & 2 & & 1 & & 3 & 5 \\
\hline 04.11.'11. & 20 & $7: 40$ & 13:00 & 2 & 5 & 2 & 3 & 2 & & & 2 & & 4 & 5 \\
\hline SUMA & 797 & & & 86 & 186 & 93 & 122 & 86 & 41 & 3 & 20 & 7 & 132 & \\
\hline
\end{tabular}

The first most extensive experiment concerns an enterprise owned by a big German firm engaged in manufacturing car components. Screenings were performed from September 19, 2011 to November 4, 2011. Monitoring included 47 cycles of different series sizes $(4-10$ pieces $)$ and the time duration ranged from the shortest $(240 \mathrm{~min})$ to the longest (420 min), with 10 - 30 instantaneous observations. The results of screening, according to the Table 1, are shown in Table 2, where only the first 5 cycles of 47 are given as well as the total result for all 47 cycles. The results are displayed per number of instantaneous observations of working time elements, the percentage of their participation in their total duration and per element of working time, as well as the total average values and standard deviations $-\mathrm{SD}$.

It is evident from the table 2 that there were 932 observations in total, while the total time for all 
cycles amounts to $15,293 \mathrm{~min}$. The average production cycle time $-t_{\mathrm{pc}}$ is $325 \mathrm{~min}$ and the average production cycle time per piece $t_{p c}$ is 56.2 min. The results are also presented by diagrams in Figures 1, 2 and 3. The diagram in Fig. 1 shows that the mean level is $\mu_{\mathrm{tpt}}=\mathrm{t}_{\mathrm{p}} /\left(\mathrm{t}_{\mathrm{pt}}+\mathrm{t}_{\mathrm{m}}+\mathrm{t}_{\mathrm{c}}+\mathrm{t}_{\mathrm{tr}}+\mathrm{t}_{\mathrm{pk}}\right)=0.7435$, while the control limits amount to $\mathrm{CC}=\mu_{\mathrm{tpt}}$ $\pm 3 \cdot \mathrm{SD} \cdot \mu_{\mathrm{tp}}=0.7435 \pm 3 \cdot 0.7435 \cdot 0.09735, \quad \mathrm{AC}=0.9606$, $\mathrm{BC}=0.5264$, The mean levels of working time elements $\mu_{\mathrm{tpt}}, \mu_{\mathrm{tm}}, \mu_{\mathrm{tc}}, \mu_{\mathrm{tr}}, \mu_{\mathrm{pk}}$ have relatively stable rates per individual cycle, i.e. when their sum total is higher, the individual levels are higher. The control time level is never higher on account of the machine time level. If we observe $\mu_{\mathrm{tm}}$ within $\mu_{\mathrm{tp}}$ we see that $\mu_{\mathrm{tm}}$ has the highest values compared to the other elements and that its level behaved within the range of normal distribution law, with an approximate mean of $\mu_{\mathrm{tm}}=0.244$. However, the control limits for this level cut too large a number of the $\mu_{\mathrm{tmi}}$ points of this level in Fig. 2. From the results shown it is evident that the process thus presented has not been mastered, but for relatively narrow limits ( $\mathrm{AC}=0.306 ; \mathrm{BC}=0.182$ ) only five points (values of $\left.\mu_{\mathrm{tm}}\right)$ have larger deviations. The cumulative value of $\mu_{\mathrm{tm}}$ approaches the mean value very quickly, which also indicates the stability of this level rate (Fig. 3). Levels of cycle time have normal distribution, since $\chi^{2}=3.070404$ and $\chi_{1}^{2}=55.76$, e.g. $\chi^{2}<\chi_{1}^{2}$.

It is inferred that to master the process in metalworking industry conditions with a cycle designed for one shift duration and a corresponding series, it is necessary to make approximately 50 daily screenings and 1000 instantaneous observations, and the production cycle time is a stochastic variable that ranges along normal distance. This example shows that the hypothesis that it is possible to apply a work sampling method in monitoring the production cycle has been proved, which represents an original approach to solving this problem.

Table 2.a: Production cycle`s elements by frequency of occurrence,

\begin{tabular}{|c|c|c|c|c|c|c|c|c|c|c|c|c|c|c|}
\hline \multirow{2}{*}{ Date } & \multirow{2}{*}{$\begin{array}{c}\mathrm{N}_{\mathrm{o}} \text { of } \\
\text { observations }\end{array}$} & \multicolumn{2}{|c|}{ Time } & \multicolumn{5}{|c|}{ Production time } & \multicolumn{5}{|c|}{ Non-production time } & \multirow{2}{*}{$\begin{array}{l}\mathrm{N}_{\mathrm{o}} \text { of } \\
\text { pieces }\end{array}$} \\
\hline & & Start & End & $t_{p t}$ & $\mathrm{t}_{\mathrm{tn}}$ & $t_{c}$ & $\mathrm{t}_{\mathrm{tr}}$ & $t_{p k}$ & $\mathrm{t}_{\mathrm{mr}}$ & $t_{t 1}$ & $t_{o}$ & $t_{b}$ & $\mathrm{t}_{\mathrm{ot}}$ & \\
\hline 19.09.2011. & 26 & $8: 30$ & 13:00 & 3 & 9 & 3 & 1 & 2 & 2 & & 2 & 1 & 2 & 7 \\
\hline 26.09 .2011$. & 18 & $8: 05$ & 13:30 & 2 & 5 & 2 & 4 & 3 & 1 & & & & 1 & 10 \\
\hline 23.09 .2011$. & 21 & & & & & & & & 21 & & & & & canceled \\
\hline 19.09.2011. & 31 & $8: 30$ & 13:00 & 2 & 9 & 3 & 3 & 3 & 2 & 1 & 2 & 1 & 4 & 7 \\
\hline 19.09.2011. & 22 & $8: 20$ & 13:10 & 2 & 7 & 4 & 1 & 3 & 1 & & 2 & & 2 & 8 \\
\hline$\ldots$ & & & & & & & & & & & & & & \\
\hline $\mathrm{N}$ & & & & & & & & & & & & & & \\
\hline$\Sigma$ & 932 & & & 100 & 229 & 118 & 142 & 99 & 47 & 3 & 25 & 15 & 154 & \\
\hline
\end{tabular}

Table 2.b: Production cycle's elements percentages of elements

\begin{tabular}{|c|c|c|c|c|c|c|c|c|c|c|c|c|c|c|c|}
\hline \multirow{2}{*}{ Date } & \multirow{2}{*}{$\mathrm{T}_{\mathrm{pc}}$} & \multicolumn{2}{|c|}{ Time } & \multicolumn{5}{|c|}{ Production time } & \multicolumn{5}{|c|}{ Non-production time } & \multirow{2}{*}{$\begin{array}{l}\mathrm{N}_{\mathrm{o}} \text { of } \\
\text { pieces }\end{array}$} & \multirow{2}{*}{$\begin{array}{l}\mathrm{T}_{\mathrm{pc}}(\mathrm{min} / \\
\text { piece })\end{array}$} \\
\hline & & Start & End & $t_{p t}$ & $\mathrm{t}_{\mathrm{tn}}$ & $t_{c}$ & $\mathrm{t}_{\mathrm{tr}}$ & $\mathrm{t}_{\mathrm{pk}}$ & $\mathrm{t}_{\mathrm{mr}}$ & $t_{\mathrm{tl}}$ & $t_{0}$ & $t_{b}$ & $t_{\mathrm{ot}}$ & & \\
\hline 19.09.2011. & 270 & $8: 30$ & 13:00 & 12 & 36 & 12 & 4 & 8 & 8 & & 8 & 4 & 8 & 7 & 38.6 \\
\hline 26.09.2011. & 325 & $8: 05$ & $13: 30$ & 11.11 & 27.78 & 11.11 & 22.22 & 16.67 & 5.56 & & & & & 10 & 32.5 \\
\hline 23.09 .2011 . & 310 & & & & & 10 & & & 100 & & & & & \begin{tabular}{|l|} 
canceled \\
\end{tabular} & 0 \\
\hline 19.09.2011. & 270 & $8: 30$ & $13: 00$ & 6.7 & 30 & 18.18 & 10 & 10 & 6.7 & 3.3 & 6.7 & 3.3 & 13.3 & 7 & 38.6 \\
\hline 19.09.2011. & 290 & $8: 20$ & $13: 10$ & 9.09 & 31.82 & 31.82 & 4.55 & 13.64 & 4.55 & & & & & 8 & 36.3 \\
\hline$\ldots$ & & & & & & & & & & & & & & & \\
\hline $\mathbf{H}$ & 100 & & & 0.107 & 0.246 & 0.127 & 0.152 & 0.106 & $\mathbf{0 . 0 5}$ & 0.003 & 0.27 & 0.016 & 0.165 & & \\
\hline
\end{tabular}

Table 2.c: Production cycle`s elements by time duration

\begin{tabular}{|c|c|c|c|c|c|c|c|c|c|c|c|c|c|c|c|}
\hline \multirow{2}{*}{ Date } & \multirow{2}{*}{$\mathrm{T}_{\mathrm{pc}}$} & \multicolumn{2}{|c|}{ Time } & \multicolumn{5}{|c|}{ Production time } & \multicolumn{5}{|c|}{ Non-production time } & \multirow{2}{*}{$\begin{array}{c}\mathrm{N}_{\mathrm{o}} \text { of } \\
\text { pieces }\end{array}$} & \multirow{2}{*}{$\begin{array}{c}\mathrm{T}_{\mathrm{pc}}(\mathrm{min} / \\
\text { piece })\end{array}$} \\
\hline & & Start & End & $t_{p t}$ & $t_{\mathrm{tn}}$ & $t_{c}$ & $t_{\text {tr }}$ & $t_{\mathrm{pk}}$ & $\mathrm{t}_{\mathrm{mr}}$ & $\mathrm{t}_{\mathrm{tl}}$ & $t_{0}$ & $t_{b}$ & $t_{\mathrm{ot}}$ & & \\
\hline 19.09.2011. & 270 & $8: 30$ & $13: 00$ & 32 & 97 & 32 & 11 & 22 & 22 & & 22 & 11 & 22 & 7 & 38.6 \\
\hline 26.09.2011. & 325 & $8: 05$ & $13: 30$ & 36 & 90 & 36 & 72 & 54 & 18 & & & & 18 & 10 & 32.5 \\
\hline 23.09 .2011$. & 310 & & & & & 18 & & & 310 & & & & & canceled & 0 \\
\hline 19.09.2011. & 270 & $8: 30$ & 13:00 & 18 & 81 & 26 & 27 & 27 & 18 & 9 & 18 & 9 & 36 & 7 & 38.6 \\
\hline 19.09.2011. & 290 & $8: 20$ & $13: 10$ & 26 & 92 & 53 & 13 & 40 & 13 & & 26 & & 26 & 8 & 36.3 \\
\hline$\ldots$ & & & & & & & & & & & & & & & \\
\hline$\Sigma$ & 15293 & & & 1632 & 3762 & 1939 & 2413 & 1709 & 704 & 40 & 376 & 271 & 2465 & & \\
\hline
\end{tabular}




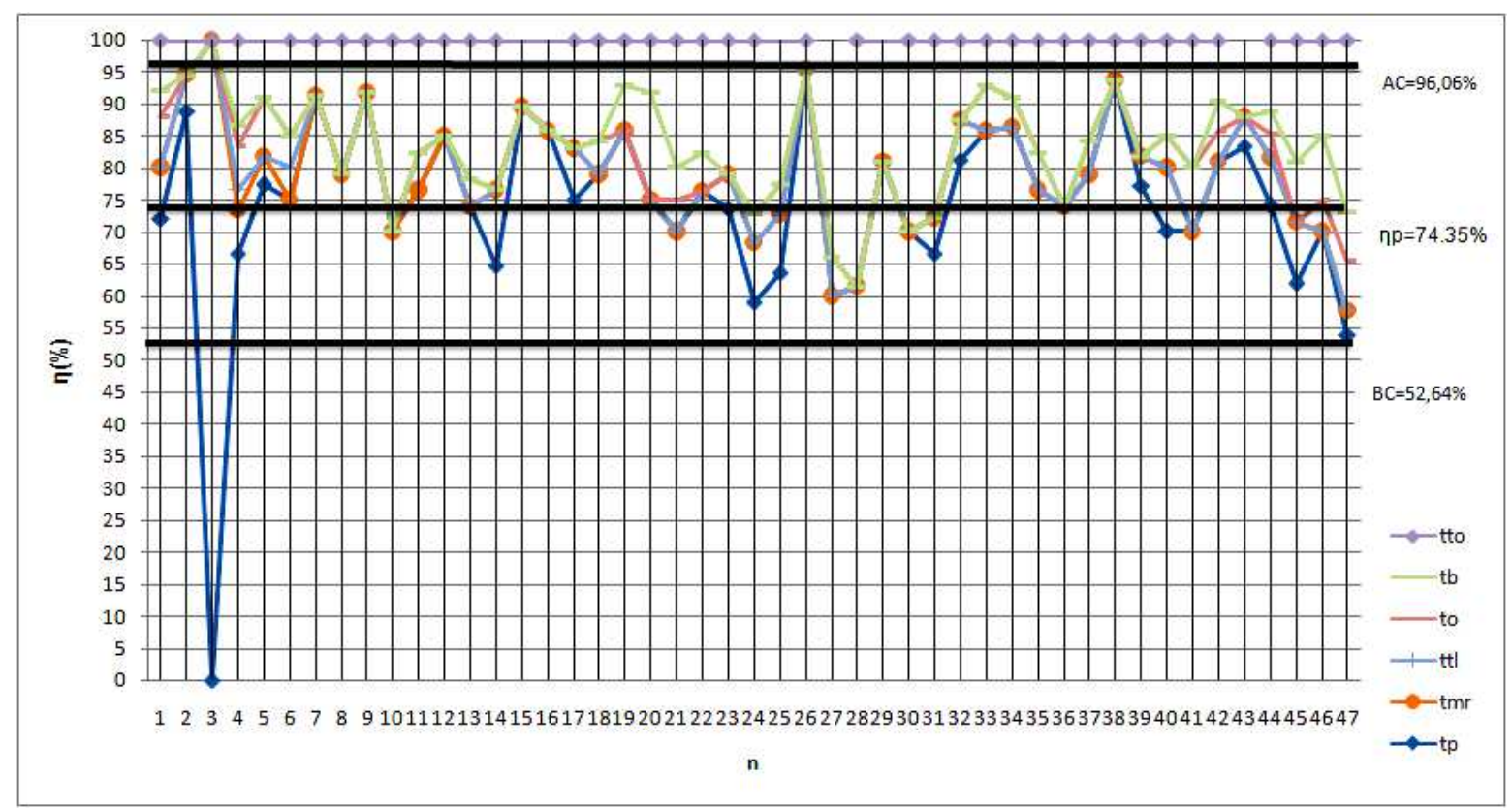

Figure 1: Diagram showing the levels of cycle time elements

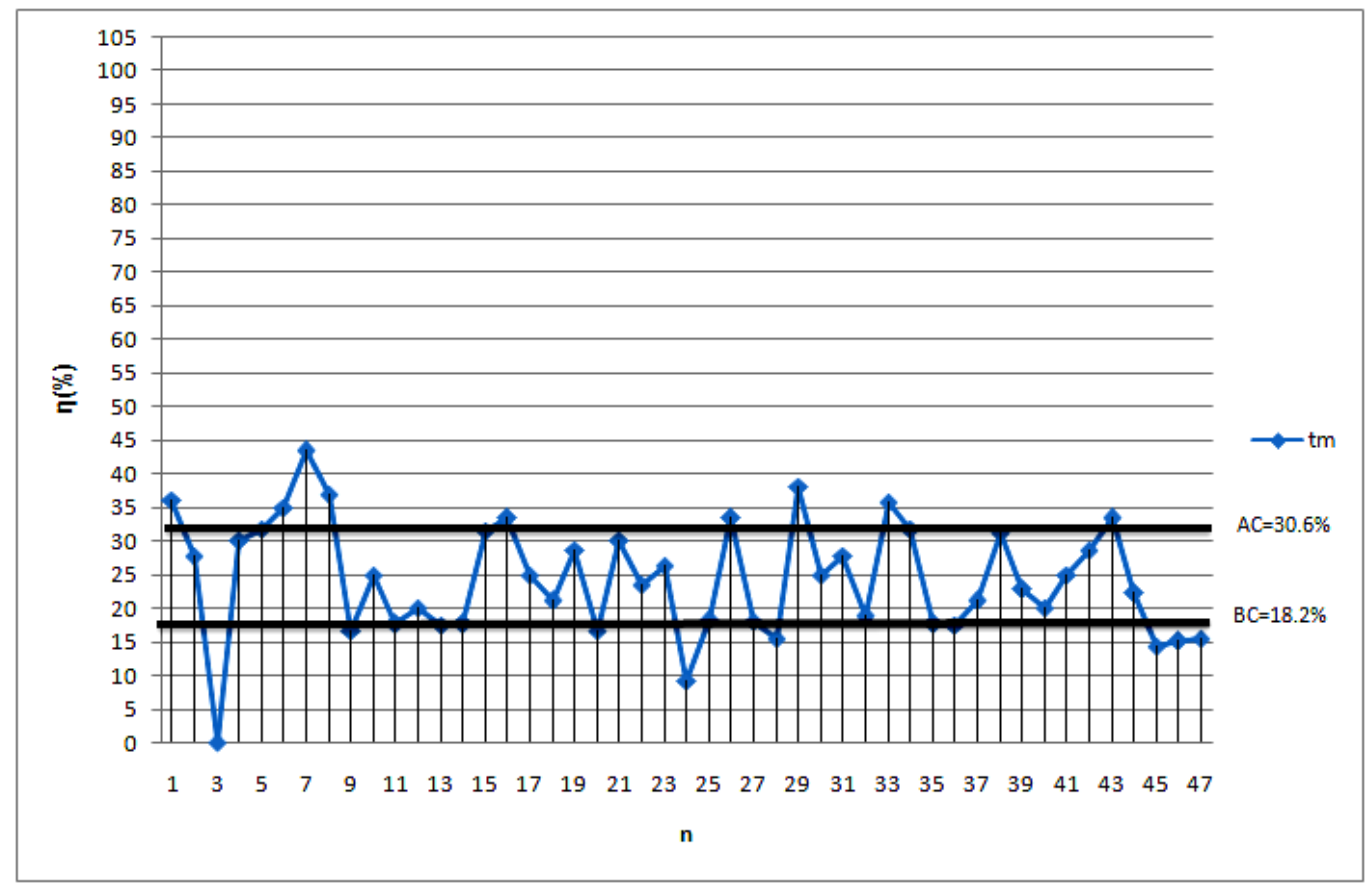

Figure 2: Machine time level

The second experiment is related to a plant that produces military and firemen clothing. Screenings were carried out from September 27, 2011 to November 13, 2011. Monitoring comprised 26 production cycles of different types there were 932 observations in total, while the total time for all cycles amounts to $15,293 \mathrm{~min}$. The average production cycle time $-t_{p c}$ is $325 \mathrm{~min}$ and the average production cycle time per unit $t_{p c}$ is 56.2 min.

Investigations related to the coefficient of running time as a function of the series size and where PC was analytically monitored from the plant's records did not include in-depth analysis of relationships between the series. 


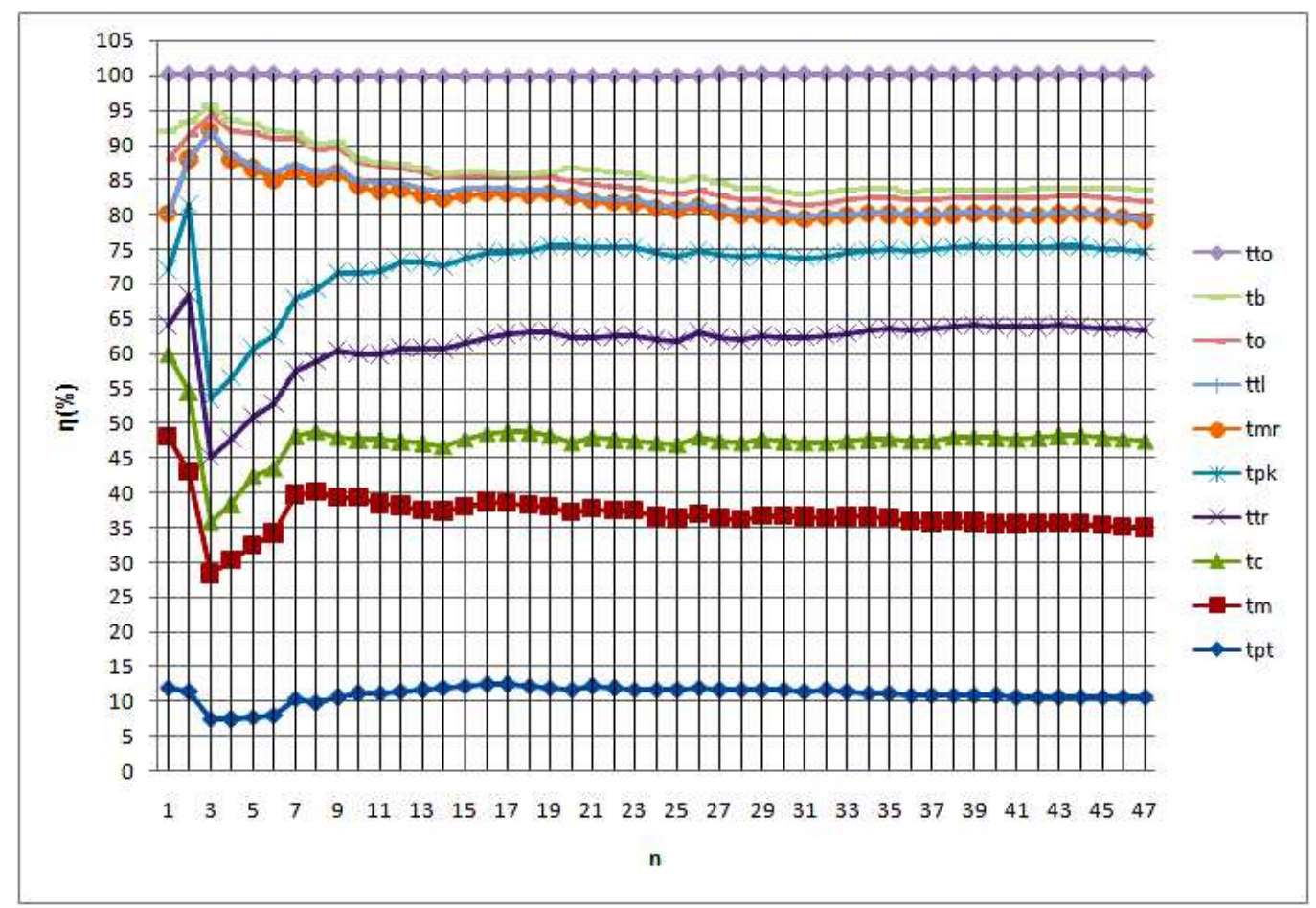

Figure 3: Cumulative production time level

Our investigations will present the analysis of PC time observed per group determined by the size of the series. Table 3 shows data for groups and PC mean values per unit in a series $\overline{\mathrm{t}}_{\mathrm{pcu}}$ (min/unit) and $\mathrm{PC}$ time $-\overline{\mathrm{t}}_{\mathrm{p}}$ for the same groups in $\%$ and $\mathrm{SD}_{\mathrm{p}} \%$. Table 4 displays the same data without groups but with the number of screening cycles and number of units in those cycles' series, with total mean value of the PC time $-\overline{\overline{\mathrm{t}}}_{\mathrm{p}} \%$ that amounts to $76 \%$.

The trends of PC time mean values $\overline{\mathrm{t}}_{\mathrm{p}}$ by cycles (groups) with identical number of units in a series in $\%$ and PC mean values per unit in a series $\overline{\mathrm{t}}_{\mathrm{p}}$ are given by a diagram in Figure 4 . Mean value for all groups is obtained using the formula:

$$
\overline{\overline{\mathrm{t}}}_{\mathrm{p}}=\sum \frac{\overline{\mathrm{t}}_{\mathrm{pi}} \cdot \mathrm{f}_{\mathrm{i}}}{\mathrm{N}}
$$

where $f_{i}$ is the number of PCs with identical number of units in a series

$$
\overline{\overline{\mathrm{t}}}_{\mathrm{p}}=\frac{85,41 \cdot 3}{46}+\ldots+\frac{79,75 \cdot 3}{46}=76 \%
$$

for a non-stratified set of data from Table 2, using the formula 2

$$
\mathrm{SD}_{\mathrm{p}}^{2}=\frac{\sum_{\mathrm{j}=1}^{1}\left(\overline{\mathrm{t}}_{\mathrm{pi}}-\overline{\overline{\mathrm{t}}}_{\mathrm{p}}\right)^{2} \mathrm{n}_{\mathrm{j}}}{\mathrm{n}}
$$

where $\mathrm{n}_{\mathrm{j}}$ is the number of cycles in a group and $\mathrm{n}$ is the total number of cycles

$$
\begin{gathered}
\mathrm{SD}_{\mathrm{p}}=4.46 \% \\
\mathrm{CC}=\overline{\overline{\mathrm{t}}}_{\mathrm{p}} \pm 3 \overline{\overline{\mathrm{t}}}_{\mathrm{p}} \mathrm{SD}_{\mathrm{p}} \\
\mathrm{CC}=76 \pm 3 \cdot 0.0446 \cdot 76=76 \pm 10.17 \\
\mathrm{AC}=86.17 \% \\
\mathrm{BC}=65.83 \%
\end{gathered}
$$

It is obvious from the diagram in Figure 4 that mathematically viewed the process is mastered, because all points of $\bar{t}_{p i}$ are within control limits BC $<\overline{\bar{t}}_{\mathrm{pi}}<\mathrm{AC},(65.83<76<86.17)$. The trend of $\overline{\mathrm{t}}_{\mathrm{pcui}}$ can be approximated by the function

$$
\overline{\mathrm{t}}_{\mathrm{pcu}}=\mathrm{c}+\frac{\mathrm{b}}{\mathrm{n}}
$$

where $\mathrm{n}$ is the number of units.

A statistical set stratification has not been successful because SD of a stratified set is:

$$
\sigma^{\prime}=\sqrt{\bar{\sigma}^{2}+\sigma^{2}}
$$

$\sigma^{`}=4.584$, and earlier (see table 2 ) calculated nonstratified $\mathrm{SD}=3.126$, according to the formula

$$
\mathrm{SD}=\sqrt{\left(\mathrm{t}_{\mathrm{pi}}-\overline{\mathrm{t}}_{\mathrm{p}}\right)^{2}}
$$




$$
\begin{gathered}
\bar{\sigma}^{2}=\frac{\sum_{j=1}^{1} \sigma_{j}^{2} n_{j}}{n} \\
\sigma^{2}=\frac{\sum_{j=1}^{1}\left(\overline{\mathrm{t}}_{p}-\overline{\overline{\mathrm{t}}}_{\mathrm{p}}\right)^{2} \mathrm{n}_{\mathrm{j}}}{\mathrm{n}}
\end{gathered}
$$

Since SD $<\sigma^{`}$ the stratification was unsuccessful, which means that in this enterprise there is no feature distinguishing PC with different number of units in a series, but the reduction of time per unit is exclusively the result of technological time, i.e., the elements of working time and number of units.

\begin{tabular}{|c|c|c|c|}
\hline Number of items (n) & $\mathrm{t}_{\mathrm{pcu}}(\min ) / \mathrm{kom}$ & $\mathrm{t}_{\mathrm{p}}(\%)$ & SD \% \\
\hline 3 & 80 & 75 & \multirow{4}{*}{7.42} \\
\hline 3 & 96 & 91.77 & \\
\hline 3 & 103.3 & 89.47 & \\
\hline$\overline{\mathrm{X}}$ & 93.1 & 85.41 & \\
\hline 4 & 80 & 85 & \multirow{5}{*}{16.14} \\
\hline 4 & 73.25 & 70 & \\
\hline 4 & 71.25 & 76.47 & \\
\hline 4 & 65.4 & 93.75 & \\
\hline$\overline{\mathrm{x}}$ & 72.48 & 81.31 & \\
\hline 5 & 60 & 78.95 & \multirow{19}{*}{28.04} \\
\hline 5 & 69.6 & 70 & \\
\hline 5 & 61.6 & 85.71 & \\
\hline 5 & 70 & 75 & \\
\hline 5 & 65.4 & 78.95 & \\
\hline 5 & 67.2 & 95.24 & \\
\hline 5 & 49.2 & 61.54 & \\
\hline 5 & 67.2 & 80.95 & \\
\hline 5 & 63.8 & 70 & \\
\hline 5 & 55.4 & 66.67 & \\
\hline 5 & 63.4 & 76.47 & \\
\hline 5 & 65.4 & 78.95 & \\
\hline 5 & 69 & 77.27 & \\
\hline 5 & 70 & 70 & \\
\hline 5 & 64 & 70 & \\
\hline 5 & 54 & 81.82 & \\
\hline 5 & 66 & 61.91 & \\
\hline 5 & 71 & 70 & \\
\hline$\overline{\bar{x}}$ & 63.29 & 74.97 & \\
\hline 6 & 51.5 & 73.91 & \multirow{11}{*}{29.64} \\
\hline 6 & 52.5 & 64.71 & \\
\hline 6 & 58.5 & 58.09 & \\
\hline 6 & 58.5 & 63.63 & \\
\hline 6 & 58.5 & 59 & \\
\hline 6 & 61.2 & 85.72 & \\
\hline 6 & 61.2 & 86.43 & \\
\hline 6 & 53.3 & 80.96 & \\
\hline 6 & 53.3 & 74.08 & \\
\hline 6 & 61.7 & 61.91 & \\
\hline$\overline{\mathrm{x}}$ & 57.02 & 70.84 & \\
\hline 7 & 38.6 & 72 & \multirow{4}{*}{16.91} \\
\hline 7 & 38.6 & 66.7 & \\
\hline 7 & 53.3 & 91.3 & \\
\hline$\overline{\mathrm{X}}$ & 43.5 & 76.67 & \\
\hline 8 & 36.3 & 73.27 & \multirow{6}{*}{10.07} \\
\hline 8 & 51 & 85.7 & \\
\hline 8 & 51 & 75 & \\
\hline 8 & 47.3 & 73.69 & \\
\hline 8 & 41.9 & 81.25 & \\
\hline$\overline{\mathrm{x}}$ & 45.5 & 77.78 & \\
\hline 10 & 32.5 & 88.88 & \multirow{4}{*}{10.53} \\
\hline 10 & 32.5 & 76.47 & \\
\hline 10 & 42 & 73.91 & \\
\hline$\overline{\mathrm{X}}$ & 35.67 & 79.75 & \\
\hline
\end{tabular}

Table 3: Cycle time per piece in the series, and production time as a percentage 
Table 4: Number of cycles and number of units in a series for enterprise I

\begin{tabular}{|c|c|c|c|c|c|}
\hline No & No of cycle & unit/ser & $\overline{\mathrm{t}}_{\mathrm{pcu}}$ (unit/series) & $\overline{\overline{\mathrm{t}}}_{\mathrm{p}}(\%)$ & SDtp \\
\hline 1 & 3 & 3 & 93.10 & 85.41 & 7.42 \\
\hline 2 & 4 & 4 & 72.48 & 81.31 & 16.14 \\
\hline 3 & 18 & 5 & 63.29 & 74.97 & 28.04 \\
\hline 4 & 10 & 6 & 57.02 & 70.84 & 29.64 \\
\hline 5 & 3 & 7 & 43.50 & 76.67 & 16.91 \\
\hline 6 & 5 & 8 & 45.50 & 77.78 & 10.07 \\
\hline 7 & 3 & 10 & 35.67 & 79.75 & 10.53 \\
\hline$\overline{\mathrm{t}}_{\mathrm{p}}(\%)$ & & & & 76 & \\
\hline
\end{tabular}

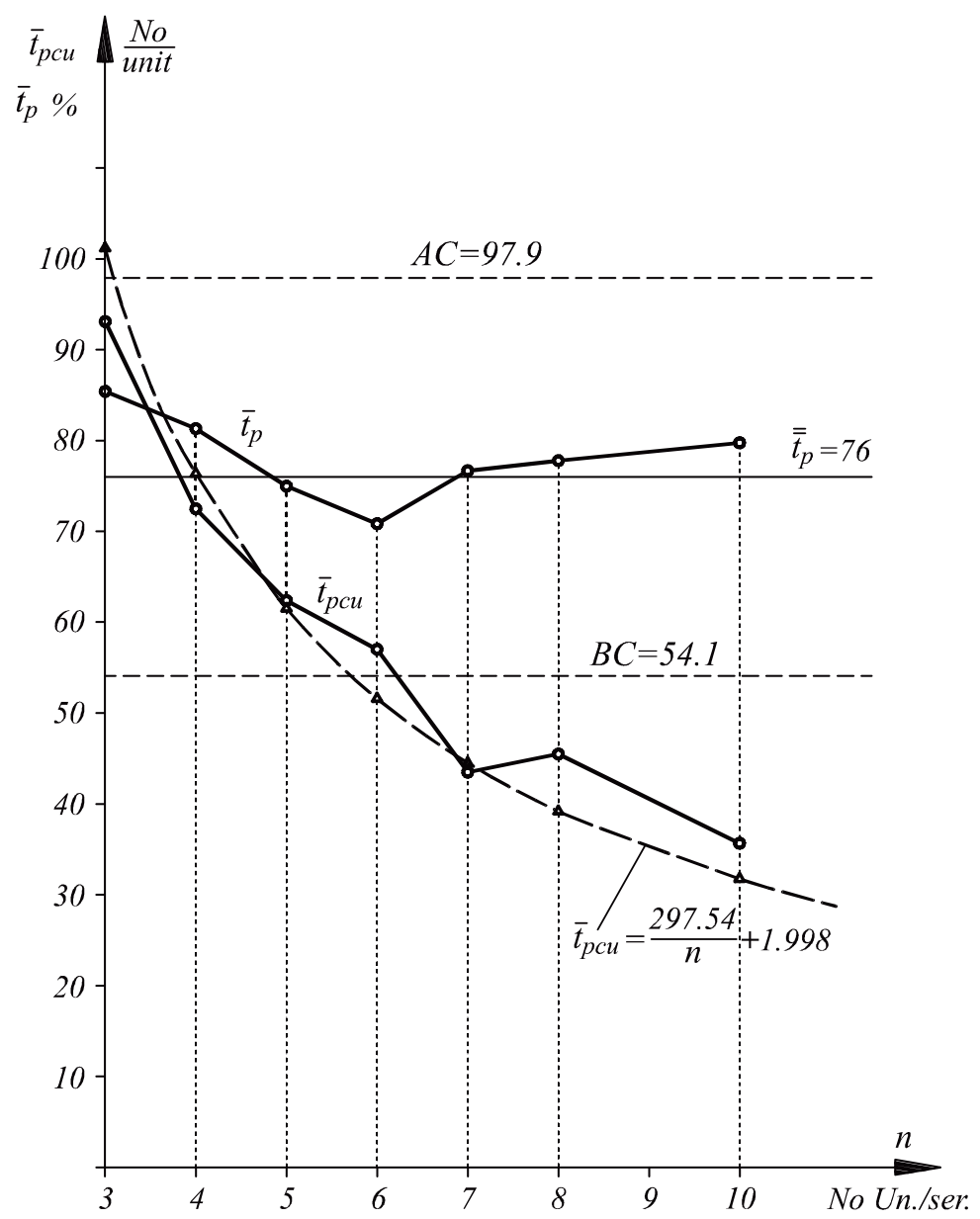

Figure 4: Trends of production time $\overline{\mathrm{t}}_{\mathrm{p}}$ mean values and PC mean values per unit in a series $\overline{\mathrm{t}}_{\mathrm{pcu}}$ for enterprise

\section{CONCLUSION}

Based on the theoretical postulates of the stochastic model for determining the elements of PC time and experimental evidence of the assumed model we infer that: PC is the most significant technical technological indicator in production and it is necessary to steadily monitor and reduce it. Instead of a demanding continuous screening and monitoring of working time elements in an analytical manner, monitoring is much simpler to perform by the original stochastic modified work sampling model. PC reduction is possible by influencing the factors related to duration of individual working time elements.Time elements trend can be mathematically monitored by establishing control limits with \pm SD from mean value; $\mathrm{PC}$ mean value for groups formed according to the number of units in a series $\overline{\mathrm{t}}_{\mathrm{pcu}}$ moves along the hyperbolic function that has asymptote c, $\overline{\mathrm{t}}_{\mathrm{pcu}}=\mathrm{c}+\frac{\mathrm{b}}{\mathrm{n}}$, and, mathematically, these groups do not behave as strata, which means they are not linked to deterministic factors of technology and number of units/series. 


\section{REFERENCES}

Agrawal, A., Minis, I., \& And Nagi, R. (2000). Cycle time reduction by improved MRP-based production planning. International Journal of Production Research, 38(18), 4823-4841.

Barbiroli, G., \& Raggi, A. (2003). A method for evaluating the overall technical and economic performance of environmental innovations in production cycles. Journal of Cleaner Production, 11(4), 365-374.

Barnes, R. (1957). Work Sampling (2nd ed.). New York: Wiley.

Čala, I., Klarin, M., Radojčić, M., \& Sajfert, Z. (2011). Development of a Stohastic Model for Determining the Elements of Production Cycle Time and Their Optimization for Serial Production in Metal Processing Industy and Recycling Processes. Journal of Engineering Management and Competitiveness (JEMC), 1(1-2), 6-9.

Elnekave, M., \& Gilad, J. (2006). Rapid video-based analysis system for advanced work measurement. International Journal of Production Research, 44(2), 271-290. doi: 10.1080/00207540500160920

Giri, B. C., \& Yun, W. Y. (2005). Optimal lot sizing for an unreliable production system under partial backlogging and at most two failures in a production cycle. International Journal of Production Economics, 95(2), 229-243.

Klarin, M. M., Cvijanović, M. J., \& Spasojević-Brkić, K. V. (2000). The shift level of the utilization of capacity as the stochastic variable in work sampling. International Journal of Production Research, 38(12), 2643-2651. doi: $10.1080 / 002075400411402$
Klarin, M. M., Milanović, D. D., Spasojević-Brkić, K. V., Misita, M., \& Jovanović, A. (2010). A method to assess capacity utilization in short cycle functional layouts. Proceedings of the Institution of Mechanical Engineers, Part E: Journal of Process Mechanical Engineering, 224(1), 49-58 doi: 10.1243/09544089JPME280

Kodek, D. M., \& Krisper, M. (2004). Optimal algorithm for minimizing production cycle time of a printed circuit board assembly line. International journal of production research, 42(23), 5031-5048.

Kun-Jen, C., Kno-Lung, H., \& Show-Ping, L. (2009). The optimal production cycle time in an integrated production -inventory model for decaying raw materials. Applied mathematical Modeling, 39, 110. doi: 10.1016/j.apm.2007.10.010

Maynard, H. B. (1971). Industrial Engineering Handbook. Pittsburgh, PA: McGraw-Hill.

Moder, J. J. (1980). Selection of work sampling observation times - Part I : Stratified sampling. AIIE Transactions, 12(1), 23-31.

Niebel, W. B. (1980). Time Study, Handbook of Industrial Engineering. New York: Wiley.

Richardson, W. J., \& Eleanor, S. P. (1982). Work Sampling, Handbook of Industrial Engineering. New York: Wiley.

Tzu-Hsien, L. (2009). Optimal production run length and maintenance schedule for a deteriorating production system. The International Journal of Advanced Manufacturing Technology, 43(9-10), 959-963. doi: 10.1007/s00170-008-1773-1

\section{ACKNOWLEDGEMENT:}

This work was supported by the Serbian Ministry of Education and Science: Grant TR 35017 